\title{
Chromosome Deletion Detected
}

National Cancer Institute

\section{Source}

National Cancer Institute. Chromosome Deletion Detected. NCI Thesaurus. Code C158863.

An indication that a chromosomal deletion was detected in a sample. 